\title{
Study of the Association Between Socio Demographic Characteristics and Dietary Diversity Among Adults Living with HIV Attending Kerugoya Referral Hospital
}

\author{
Githongo Faith Wangari, Otieno Samwel Boaz \\ Department of Community Health, Faculty of Health Sciences, Great Lakes University, Nairobi, Kenya
}

Email address:

samwelbotieno@yahoo.com (O. S. Boaz)

\section{To cite this article:}

Githongo Faith Wangari, Otieno Samwel Boaz. Study of the Association Between Socio Demographic Characteristics and Dietary Diversity Among Adults Living with HIV Attending Kerugoya Referral Hospital. Journal of Health and Environmental Research.

Vol. 7, No. 4, 2021, pp. 192-197. doi: 10.11648/j.jher.20210704.14

Received: September 28, 2021; Accepted: October 21, 2021; Published: October 29, 2021

\begin{abstract}
PLWHIV needs to eat a balanced diet and a diverse diet with foods in sufficient quantities to meet their energy, protein and micronutrient needs. The purpose of this study was to determine the dietary diversity among adults living with HIV in the Kerugoya Comprehensive clinic, Kirinyaga County, Kenya. The study adopted analytical cross-sectional design. Data was collected from a sample of 169 persons and stratified random sampling technique was used to determine the proportion of each gender for the study from Kerugoya Comprehensive clinic ART booking register. Quantitative and qualitative methods which include structured questionnaire, focused group discussions and In-depth Interviews were used in collection of data. Pre testing of the questionnaires was done to $10 \%$ of sample in a nearby public facility Kagumo Health Centre Comprehensive Care Clinic. Confidentiality was observed by coding the questionnaires and names were not written. Informed consent was sought from the respondents before the data collection. Privacy was also observed as interviews were conducted in closed rooms. Completed questionnaires were kept in the cabinet under lock and key for safety and security reasons. Descriptive statistics (frequencies and percentages) and inferential statistics (Chi square) were used for data analysis. All quantitative data were analysed using SPSS version 20 while qualitative data were analysed thematically using computer software NVIVO. The study established that demographic factors are associated with dietary diversity among HIV positive adults attending Kerugoya Comprehensive clinic. Socio-demographic factors associated with dietary diversity were gender, marital status and levels of education ( $p<0.05)$. From the findings, interventions targeting individuals with demographic factors associated with low dietary diversity scores can be organized. This can be done by the county governments, NGOs and faith-based organizations. For gender, interventions could target the male PLWHIV, unmarried individuals within this category should also be targeted. Such interventions should aim at ensuring positive dietary diversity behaviours among PLWHIV.
\end{abstract}

Keywords: Diet, PLWA, HIV, Diversity

\section{Introduction}

Studies indicate that socio-demographic factors are pointers to population behaviour. For instance, it has been pointed out that socio-demographic factors influence marital happiness, health and longevity [6]. Based on this reasoning, socio-demographic factors may have a bearing on dietary diversity. A study conducted in Tanzania revealed that older adults consume low food variety with inadequate dairy products, fruits, and vegetables [2]. Another cross-sectional study among elderly respondents in South Africa also revealed low mean dietary diversity score of and food variety score among the aged [9].

A study by revealed that lactating women had low dietary diversity scores away from the daily recommended intakes for vitamins A, C, E and B-6, and iron and zinc [4] and male-headed households showed greater food security [8]. A study in Ethiopia also established that higher education is associated with the regular consumption of a wider variety of foods $[10,3]$.

Earlier studies established that food variety is higher among urban populatios compared to rural populations [12]. Urban 
populations was also found to eat more frequently and to have higher micronutrient intake compared their rural counuter parts $[11,1]$. Demographic factors have also been found to affect food consumption [13]. For example married persons tend to consume less alcohol but more serving of deserts comapred to unmarried persons. Large family size is found to have effect on food security [5]. Religious and ethnicity was also been found to affect dietary scores, with Christians women having higher scores compared to muslims women [7].

A cross sectional study done in Motta town, Northwest Ethiopia among HIV adults patients attending Public Health facilities reported that 127 participants who were married had a high IDDS while 65 umarried had a low IDDS whereas in another study 162 participants who were married had a high IDDS and 56 had a low IDDS [10]. An institution based cross sectional study done in Eastern Ethiopia among HIV positive adults attending ART clinics by Mulatuet al. (2017) indicated 30 male participants had a low IDDS while 84 had high IDDS whereas 57 females had low IDDS while 132 had high IDDS. These finding illustrate that males are more likely to have a low IDDS as compared to the Demographic factors considered for analysis included sex, age, marital status, level of education and number of people in the households. The factors were cross tabulated against the IDDS. Table 2 presents the demographic factors associated with IDDS.

\section{Materials and Methods}

\subsection{Study Design}

This was cross sectional analytical study design to determine association between social demographic characteristics, Knowledge of adequate diet, economic status, social support status and dietary diversity. This was made possible through mixed methods research where both qualitative and quantitative methods were used.

\subsection{Study Area}

The study was conducted in Kerugoya County Referral Hospital comprehensive care clinic which started in the year 2004. The hospital is a level four facility which is the biggest hospital in Kirinyaga County as well as the referral hospital in this county. It is situated in Kerugoya town, Kirinyaga Central sub county, Kirinyaga County, Kenya. The CCC is the largest care and treatment centre for PLWHIV in the county. TheCCC was the first to offer HIV services in Kirinyaga County and has the largest enrolment for HIV care. PLWHIV ever enrolled for care is were 3845 and at the time of study were approximately 2000 . The clinic provides antiretroviral therapy (ART) programme which includes HIV testing and counselling, provision of antiretroviral (ARVs) drugs, psychosocial support services, nutrition advice counselling services and treatment of opportunistic infections.

\subsection{Study Population}

The study population comprised of all adult HIV positive adults' males and females aged over 18 years attending
Kerugoya County Referral Hospital comprehensive care clinic. The unit of analysis was males and females. The proportion of women accessing the facility is about $70 \%$ while $30 \%$ are men. The study population were accessed at the Kerugoya County Referral Hospital comprehensive care clinic.

\subsection{Sample Size Determination}

The study employed both stratified random sampling and purposive sampling techniques to come up with the sample size.

A total of 169 sample was computed based on earlier suggestions [14-16]

$$
\mathrm{n}=\mathrm{Z}^{2} \alpha / 2 \mathrm{PQ}
$$

Where $\mathrm{n}=$ required sample size

$\mathrm{Z} \alpha / 2_{2}=1.96$ (Critical value of the standard normal distribution corresponding to error rate $\alpha / 2$ at the level of significance $\sigma=0.05(5 \%)$.

$\mathrm{P}=$ Estimated proportion of the population with inadequate dietary intake. A value of $10.3 \%$ representing the prevalence estimates of adult malnutrition, as a proxy for dietary quality in sub-Saharan African countries was used (Olalekan and Uthman, 2008).

$\mathrm{Q}=(1-\mathrm{P})$, which represents the estimated proportion of the population with adequate dietary intake

$$
\mathrm{n}=\frac{1.96^{2} \times 0.897 \times 0.103}{0.05^{2}}=\frac{3.8416 \times 0.092=0.355}{0.0025}=141.9
$$

$20 \%$ of the original sample size was added to cater for non-response making the sample of $(141+28)$ respondents.

$\mathrm{n}=169$

The study also purposively sampled 24 participants from the facility register to participate in the Focus group discussions and 6 comprehensive care facility providers to participate in in depth Interviews.

\subsection{Sampling Technique}

The study utilized stratified random sampling to select the participants. Stratified random sampling helps in identifying sub groups in the population and their proportions, in this study these were males and females. The patients were selected from the comprehensive care booking register. The sampling frame was a list of PLWHIV, both males and females. Their ratio was used to determine the proportion of each sex to be included in the sample size.

\subsection{Inclusion and Exclusion Criteria}

The study included respondents who had the following conditions,

1. HIV positive adults aged 18 to 65 years.

2. Attending Kerugoya County Referral Hospital comprehensive care clinic during the study period.

3. Consented to participate in the study.

Those Excluded from the study were;

1. Respondents who were too sick and un-able to get through the interview. 
2. Respondents who's previous 24-hour meals were unusual such as those eaten at feasts or special occasions away from home.

3. HIV positive adults aged 18 to 65 years attending Kerugoya County Referral Hospital comprehensive care clinic for the first time.

\subsection{Sampling Procedure}

All adults attending Kerugoya County Referral Hospital comprehensive care clinic During the study Principal investigator together with two assistants who are nurses working in triage selected respondents meeting the set criteria, and willing to to take part in the study. At least four respondents were recruited per day.

Respondents for the FGD were recruited by telephone. Those willing were grouped into three categories. The youth, the Female adults and male a dults. Once they gave consent they put through FGD and responses taken by a research assidstant. Transcripts were also recorded by tape to help interpretation of interview notes.

\subsection{Data Collection Methods}

Quantitative and qualitative data collections methods were used. This included structured questionnaires, face to face interviews, checklist for food groups as per guidelines for measuring IDDS, focused group discussion and key informant interview. Data on socio demographic characteristics such as gender, age, occupation were collected using a questionnaire. Standardized IDDS tool with a 24-hour food recall method (Fanta, nutrition and technical assistance, 2007) was used to assess dietary diversity of adult patients living with HIV/AIDS. Qualitative data collection methods (IDIs and FGDs) were used to collect qualitative data from the respondents. A total of 6 IDIs and 3 FGDs were conducted. Participants in the FGD were between 6-8. Informants for the IDI were drawn from the comprehensive care unit workers while participants in the FGD were sampled conveniently from the study population.

\subsection{Data Collection Tools}

Quantitative data was collected using structured questionnaires, face to face interviews, checklists, 24-hour recall method of foods eaten. Qualitative data was collected using focus group discussion guide, in-depth interview schedule as data collection tools.

\subsection{Data Collection Procedure}

The researcher sought permission for data collection at the county through the Kerugoya District hospital ethical research review committee. After obtaining the permission, pretesting of the questionnaires for reliability and validity was done. Two research assistants were recruited and trained for two days on how to use and fill the questionnaires, ethical issues on how to observe privacy, respect and confidentiality for the participants and also how to get informed consent from the participants before data gathering. They will be also trained on how to conduct face to face interview using the 24-hour recall period. The researcher supervised the data collection to ensure completeness and accuracy of the forms.

The collected questionnaires were kept by the researcher in the cabinet under a lock and key every day after data collection to ensure that they are safe and secure. The researcher and the research assistants edited and cleaned the data collected by checking the filled-up questionnaires for completeness and errors. The researcher after the data cleaning developed coding scheme by assigning numbers to particular responses and coding them to ensure appropriate data analysis. The coded data were defined, labelled and entered into the computer. Data analysis was done using SPSS for the quantitative data and NVIVO for the qualitative data. Data presentation is in the form of tables and charts. Quantitative data is summarized through descriptive (frequencies and percentages) and association between the dependent and independent variable ascertained through chi square tests and regression analysis (95\% confidence level).

\section{Results}

\subsection{Demographic Characteristic of Study Population}

Demographic factors considered included sex, age, marital status, Level of education and main source of food. Table 1 below presents the demographic characteristics of the respondents.

Table 1. Demographic characteristics of the respondents.

\begin{tabular}{|c|c|c|}
\hline & Frequency & Percent \\
\hline \multicolumn{3}{|l|}{ Sex } \\
\hline Male & 45 & 28.8 \\
\hline Female & 111 & 71.2 \\
\hline \multicolumn{3}{|l|}{ Age } \\
\hline $18-25$ & 14 & 9 \\
\hline $26-33$ & 19 & 12.2 \\
\hline $34-41$ & 33 & 21.2 \\
\hline $42-49$ & 50 & 32.1 \\
\hline $50-57$ & 31 & 19.9 \\
\hline $58-65$ & 5 & 3.2 \\
\hline Over 65 years & 4 & 2.6 \\
\hline \multicolumn{3}{|l|}{ Marital Status } \\
\hline Married & 70 & 44.9 \\
\hline Widow & 15 & 9.6 \\
\hline Widower & 1 & 0.6 \\
\hline Separated & 7 & 4.5 \\
\hline Divorced & 6 & 3.8 \\
\hline Single & 56 & 35.9 \\
\hline \multicolumn{3}{|l|}{ Level of education } \\
\hline None & 5 & 3.2 \\
\hline Primary & 87 & 55.8 \\
\hline Secondary & 48 & 30.8 \\
\hline College/University & 15 & 9.6 \\
\hline \multicolumn{3}{|l|}{ Main source of food } \\
\hline Purchase & 101 & 64.7 \\
\hline Food aid/gift & 1 & 0.6 \\
\hline Own production & 52 & 33.3 \\
\hline Exchange for labour & 2 & 1.3 \\
\hline Total & 156 & 100 \\
\hline
\end{tabular}


The findings indicate that above $70 \%$ of the respondents were female. Of the respondents sampled, $32.1 \%$ were aged between $42-49 \%$ years $34-41$ years while $21.1 \%$ were of ages between $34-41$ years. About $44.9 \%$ of the respondents were married, $35.9 \%$ were single while $9.6 \%$ were widows. Those with primary school education were $55.8 \%$ while those with secondary school education were $30.8 \%$. The findings also indicate that $64.7 \%$ of the respondents purchased their food while $33.3 \%$ produced own food.

Dietary diversity was measured using number of meals consumed and the food categories in the meals consumed. Figure 1 presents the findings.

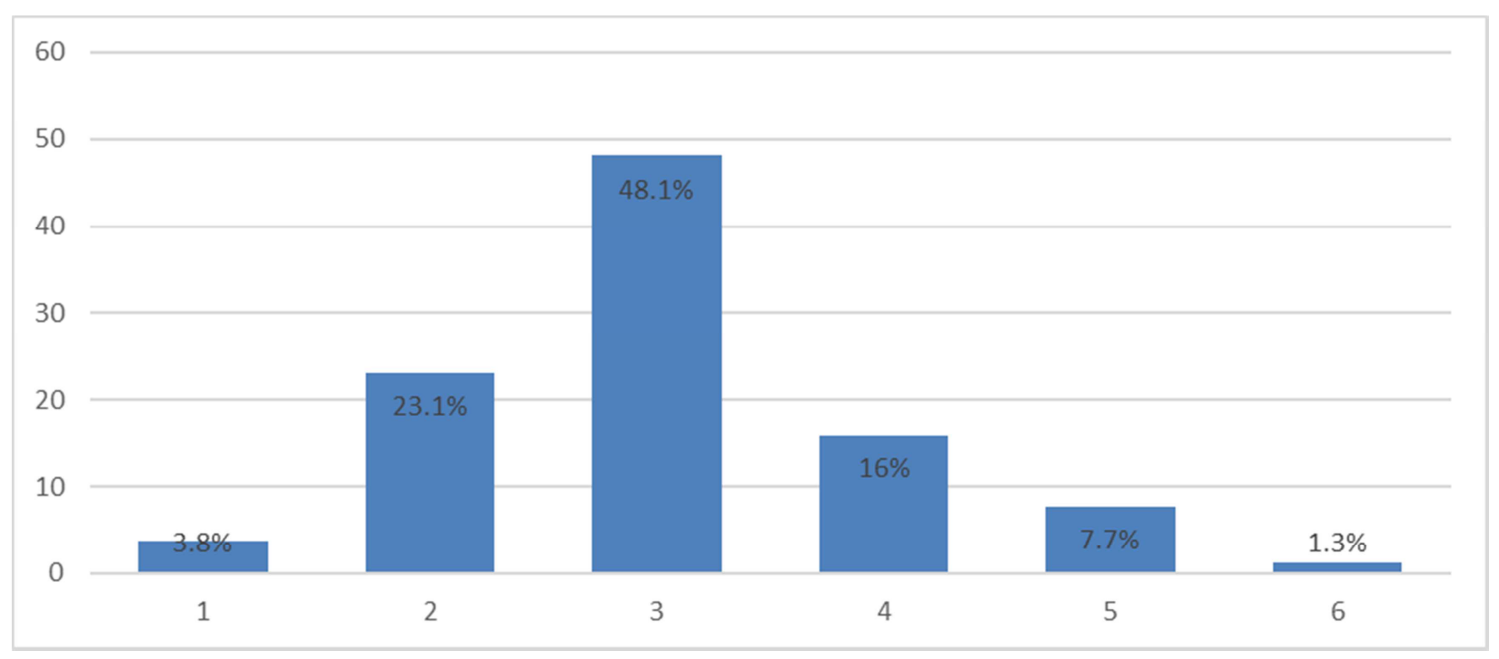

Figure 1. Number of meals taken.

Abouthalf of participants (48.1\%) had 3 meals per day. Another $23.1 \%$ had only 2 meals a day. Those who had 4 meals were 16 . Most commonly eaten foods were starch/root tubers foods $(97.4 \%)$, pulses, legumes and nuts (95.5\%) with oils and fats $(92.5 \%)$ and the least eaten foods were mainly fruits at about $30.1 \%$. This was as shown in Table 2 .

Table 2. Food categories taken.

\begin{tabular}{lll}
\hline & Frequency & Percent \\
\hline Consumed Starch/root tubers & 152 & 97.4 \\
Consumed fruits & 47 & 30.1 \\
Consumed Vegetables & 131 & 84 \\
Consumed Water & 148 & 94.9 \\
Consumed Minerals Supplements & 5 & 3.2 \\
Consumed Proteins & 136 & 87.2 \\
Consumed fats and oils & 145 & 92.9 \\
Pulses, Legumes and nuts & 149 & 95.5 \\
\hline
\end{tabular}

Most respondents $67.6 \% \%$ ate at least 5 food types and $17.6 \%$ ate at least 6 food types. The mean number of types of food eaten was 5.23 (SD1.44) with a range of $1-8$ food types. Majority of the respondents were in the medium IDDS group and only $14.5 \%$ of the respondents were in the lowest IDDS tercile as shown in Table 3.

Table 3. Three Category IDDS.

\begin{tabular}{lll}
\hline Tercile & Frequency & Percent \\
\hline Low IDDS (1 - 3 food groups) & 23 & 14.5 \\
Medium IDDS (4 - 5 food groups) & 105 & 67.6 \\
High IDDS (6 or more food groups) & 27 & 17.6 \\
Total & 156 & 100 \\
\hline
\end{tabular}

Data was further summarized to obtain two categories of IDDS (low and high IDDS). In this category, about $72.7 \%$ of the respondents had high IDDS (5-8 food groups) while 27.3\% had low IDDS (1-4 food groups). Table 4 below presents the two categories of IDDS.

\subsection{Association Between Socio-Demographic Factors and IDDS}

Demographic factors considered for analysis included sex, age, marital status, level of education and number of people in the households. The factors were cross tabulated against the IDDS. Table 4 presents the demographic factors associated with IDDS.

Demographic factors with significant statistical association with dietary diversity included gender, marital status and level of education. Female respondents were 0.2 times less likely to have high dietary diversity score. Also, respondents who were widows/widowers were more likely to have low dietary diversity scores $(\mathrm{OR}=5.1)$. Those who were separated / Divorced were 1.8 times more likely to have low dietary diversity. This was also true of single individuals who were 1.5 times more likely to have low dietary diversity scores. The findings also reveal that respondents who had primary school education, secondary school education and college/ University levels of education were less likely to have low dietary diversity scores as compared to those with no education $(\mathrm{OR}=0.1)$. Both the In-depth interviews and the focused group discussions also revealed emergent theme along the demographic factors associated with dietary diversity. Most participants were of the opinion that demographic factors are issues one would not have control over. It emerged that such factors including gender, marital status and levels of education were associated with dietary diversity. 
Table 4. Demographic factors associated with IDDS.

\begin{tabular}{|c|c|c|c|c|c|}
\hline \multicolumn{6}{|l|}{ Dietary Diversity } \\
\hline \multicolumn{6}{|l|}{ Characteristics } \\
\hline & Total N=156 (\%) & High $N=113$ & Low $(\mathrm{N}=43$ & Odds ratio $(95 \% \mathrm{CI})$ & p-value \\
\hline \multicolumn{6}{|l|}{ Sex } \\
\hline Male & $45(28.8)$ & 21 & 24 & 1 & \multirow{2}{*}{$<0.0001$} \\
\hline Female & $111(71.2)$ & 92 & 19 & $0.2(0.08-0.39)$ & \\
\hline \multicolumn{6}{|l|}{ Age } \\
\hline $18-25$ & $14(9)$ & 8 & 6 & 1 & \multirow{4}{*}{0.092784} \\
\hline $26-33$ & 19 (12.2) & 10 & 9 & $1.2(0.30-4.82)$ & \\
\hline $34-41$ & $33(21.2)$ & 26 & 7 & $2.8(0.7-10.7)$ & \\
\hline$>41$ & $90(57.9)$ & 69 & 21 & $2.5(0.8-7.9)$ & \\
\hline \multicolumn{6}{|l|}{ Marital Status } \\
\hline Married & $70(44.9)$ & 56 & 14 & 1 & \multirow{4}{*}{0.032658} \\
\hline Widow/Widower & $16(10.2)$ & 7 & 9 & $5.1(1.63-16.21)$ & \\
\hline Separated/Divorced & $13(8.3)$ & 9 & 4 & $1.8(0.48-6.62)$ & \\
\hline Single & $56(35.9)$ & 41 & 15 & $1.5(0.64-3.36)$ & \\
\hline \multicolumn{6}{|l|}{ Level of education } \\
\hline None & $5(3.2)$ & 1 & 4 & 1 & \multirow{4}{*}{0.048983} \\
\hline Primary & $87(55.8)$ & 62 & 25 & $0.1(0.01-0.95)$ & \\
\hline Secondary & $48(30.8)$ & 37 & 11 & $0.1(0.01-0.74)$ & \\
\hline College/University & 1599.6) & 12 & 3 & $0.1(0.01-0.78)$ & \\
\hline \multicolumn{6}{|c|}{ Number of people in the Household } \\
\hline$<4$ & $80(51.3)$ & 55 & 25 & 1 & \multirow{2}{*}{0.290489} \\
\hline$>=4$ & $76(48.7)$ & 58 & 18 & $0.7(0.34-1.39)$ & \\
\hline
\end{tabular}

\section{Discussion}

The study established that demographic factors are associated with dietary diversity among HIV positive adults attending Kerugoya County Referral Hospital. Specifically, gender, marital status and level of education were significantly associated with dietary diversity. Women were found to be more likely to have high dietary diversity than me. Also, those who were married recorded higher dietary diversity scores than the unmarried. Similarly, level of education increased with dietary diversity scores. These findings lead to an understanding that dietary diversity among HIV positive adults attending Kerugoya County Referral Hospital is associated with socio-demographic factors. In other studies, however, women were found to have low dietary diversity scores than men [8]. This finding could be explained by the geographical and time differences in the present study. The findings of this study with respect to marital status and levels of education affirms those of $[4,3,10]$ who also found marital status and levels of education to be associated with dietary diversity scores.

\section{References}

[1] Annan, R. A., Jackson, A. A., Margetts, B. M., \& Vorster, H. (2015). Dietary patterns and nutrient intakes of a South African population and asymptomatic people infected with Human Immunodeficiency Virus: The transition health and urbanisation in South Africa (Thusa) study. African Journal of Food, Agriculture, Nutrition and Development, 15 (2), 9838-9854.

[2] Cockx, L., Colen, L., De Weerdt, J., \& Paloma, G. Y. (2019). Urbanization as a driver of changing food demand in Africa: evidence from rural-urban migration in Tanzania.
[3] Desta, M., Akibu, M., Tadese, M., \& Tesfaye, M. (2019). Dietary Diversity and Associated Factors among Pregnant Women Attending Antenatal Clinic in Shashemane, Oromia, Central Ethiopia: A Cross-Sectional Study. Journal of Nutrition and Metabolism, 2019.

[4] Engidaw, M. T., Gebremariam, A. D., Tiruneh, S. A., Asnakew, D. T., \& Abate, B. A. (2019). Dietary diversity and associated factors among lactating mothers in Debre Tabor General Hospital, Northcentral Ethiopia. International Journal, 5 (1), 17.

[5] Gitagia, M. W., Rose Chepchirchir Ramkat, D. M. M., Termote, C., Covic, N., \& Cheserek, M. J. (2019). Determinants of dietary diversity among women of reproductive age in two different agro-ecological zones of Rongai Sub-County, Nakuru, Kenya. Food \& Nutrition Research, 63.

[6] Lawrence, E. M., Rogers, R. G., Zajacova, A., \& Wadsworth, T. (2019). Marital happiness, marital status, health, and longevity. Journal of Happiness Studies, 20 (5), 1539-1561.

[7] Lemeshow, A. R., Rimm, E. B., Hasin, D. S., Gearhardt, A. N., Flint, A. J., Field, A. E., \& Genkinger, J. M. (2018). Food and beverage consumption and food addiction among women in the Nurses' Health Studies. Appetite, 121, 186-197.

[8] Nyangasa, M. A., Buck, C., Kelm, S., Sheikh, M., \& Hebestreit, A. (2019). Exploring Food Access and Sociodemographic Correlates of Food Consumption and Food Insecurity in Zanzibari Households. International journal of environmental research and public health, 16 (9), 1557.

[9] Saha, S., Abu, B. A. Z., Oldewage-Theron, W., \& Egal, A. (2019). Available food options at local shops in relation to food insecurity among older adults in Sharpeville, South Africa. African Journal of Food, Agriculture, Nutrition and Development, 19 (2), 14500-14516.

[10] Tesfaw, A., Jara, D., \& Temesgen, H. (2018). Dietary Diversity and Associated Factors among HIV Positive Adult Patients Attending Public Health Facilities in Motta Town, East Gojjam Zone, Northwest Ethiopia, 2017. Advances in Public Health, 2018. 
[11] Yang, Yang, Xiao-Mei Hu, Tian-Jiao Chen, and Ming-Jie Bai. "Rural-urban differences of dietary patterns, overweight, and bone mineral status in Chinese students." Nutrients 8, no. 9 (2016): 537.

[12] Zang, Jiajie, Huiting Yu, Zhenni Zhu, Ye Lu, Changhe Liu, Chunxia Yao, Pinqing Bai et al. "Does the dietary pattern of shanghai residents change across seasons and area of residence: assessing dietary quality using the Chinese diet balance index (DBI)." Nutrients 9, no. 3 (2017): 251.

[13] Uthman, O. A. (2008) Prevalence and pattern of HIV-related malnutrition among women in sub-Saharan Africa: a meta-analysis of demographic health surveys. BMC Public Health 8, 226 https://doi.org/10.1186/1471-2458-8-226

[14] Kish, L. (1959). Some Statistical Problems in Research Design. American Sociological Review, 24 (3), 328-338.

[15] Fisher RA, Yates F 1938, Statistical tables for biological, agricultural, and medical research Edinburg, tweddale, coart London, 39A, wellbek street ISBN 0-01-844720-4.

[16] Otieno S. B (2015) Role of Selenium in HIV progression in HIV1 positive children in Kisumu County Kenya, THESIS, Kenyatta University, Kenya. 